\title{
Glass Difractive Optical Elements (DOEs) with Complex Modulation DLC Thin Film Coated
}

\author{
Marina Sparvoli*, Ronaldo Domingues Mansano \\ Laboratório de Sistemas Integráveis, Departamento de Engenharia de Sistemas Eletrônicos, \\ Escola Politécnica da Universidade de São Paulo - USP, \\ Av. Prof. Luciano Gualberto, trav. 3, 153, 05508-900 São Paulo - SP, Brazil
}

Received: December 15, 2007; Revised: August 5, 2008

\begin{abstract}
We developed a complex (amplitude and phase) modulation Diffractive Optical Element (DOE) with four phase levels, which is based in a glass substrate coated with DLC (Diamond Like Carbon) thin film as the amplitude modulator. The DLC film was deposited by magnetron reactive sputtering with a graphite target and methane gas in an optical glass surface. The glass and DLC film roughness were measured using non destructive methods, such as a high step meter, Atomic Force Microscopy and Diffuse Reflectance. Other properties, such as refractive index of both materials were measured. The DOEs were tested using $632.8 \mathrm{~nm}$ HeNe laser.
\end{abstract}

Keywords: diamond like carbon, glass, diffractive optical elements

\section{Introduction}

Diffractive optical elements (DOEs) are wavefront processors used to change the distribution of an incident light beam with known properties into a specified pattern ${ }^{1}$. There are two main types of DOE: one is amplitude based and the other is phase-contrast. The phasecontrast is more efficient than the amplitude DOEs ${ }^{2}$. The objective of this study was the development of diffractive optical elements (DOE's), fabricated on B 270 glass substrate, with four phasemodulation and amplitude modulation. The amplitude modulation is produced by DLC thin films (Diamond Like Carbon) deposited over glass. A DOE is a component that works according to Huygens principle ${ }^{3-7}$ and modifies wavefronts by segmenting and redirecting the segments through the use of interference and phase control.

Compared with refractive elements, DOE's are lighter, occupy a relatively lesser volume and they can be fabricated using microelectronic processes. Thus they can be built in large scale with high reproducibility, and eliminating almost all the stages traditionally used in optic elements fabrication, as abrasion and burnishing 8 Furthermore, the advantages include:

- Their functional flexibility; whereby an element can perform one or more complex functions simultaneously e.g. beam splitting and focusing;

- Ease of replication makes production fast, affordable and relatively simple; and

- Parallel performance of similar or different functions such as the multifocus hololens array for parallel pattern recognition.

In this work it is presented the development of diffractive optic devices based in optical glass B 270 from Schott, which present low fabrication cost and have a large transmittance range from 300 to $1,000 \mathrm{~nm}$, becoming possible their use in visible light range.

These devices can be applied in the prototyping of optic systems that can be used in day-by-day equipments such as sensor of position and presence, artificial vision, etc. ${ }^{9-11}$

The DLC film of this device works as an amplitude modulator Diamond like carbon (DLC) is a metastable form of amorphous carbon containing a significant fraction of sp3 bond. It can have a high mechanical hardness, chemical inertness, optical transparency, and it is a wide band gap semiconductor. DLC films have widespread applications as protective coatings and microeletromechanical devices $(\mathrm{MEMs})^{12}$. The $\mathrm{sp}^{2}$ - bonded carbons form $\pi-\pi$ bonding network that is responsible for the optical properties like the optical gap and infrared refractive index ${ }^{16}$.

\section{Materials and Methods}

\subsection{Devices with four phase levels fabrication}

The device fabrication folowed the sequence of Figure 1. For the development of this work, Schott B 270 optical glass substrates with $75 \mathrm{~mm}$ diameter and $1 \mathrm{~mm}$ thickness with a thermally evaporated thin layer of aluminium were used.

To obtain the two first levels (after the photolitographic process to obtain the $\pi / 2$ phase, aluminum wet etching and photoresist remotion) plasma etching process was peformed with pure $\mathrm{CF}_{4}$ plasma with $48 \mathrm{sccm}$ gas flow. The etching was made with 100 mTorr pressure, $400 \mathrm{~W}$ RF power and under temperature of $5^{\circ} \mathrm{C}$.

With the intention to obtain the final device with four phase levels that will operate with $\mathrm{HeNe}$ laser (wavelenght $=632.8 \mathrm{~nm}$ ), it was made a photo litographic process again for the $\pi$ phase, aluminum wet etching followed by photo resist remotion and finally, glas etching process with the same parameters of the first etching.

\subsection{DLC deposition process}

After the second plasma etching and photoresist remotion, the deposition of thin amorphous carbon films was performed by magnetron sputtering system using a graphite pure (99.999\%) target with $150 \mathrm{~mm}$ diameter. Using a vacuum system composed by a turbo-molecular pump and a root pump, a (residual) pressure of $4.10^{-6}$ Torr was obtained. The process pressure $5.10^{-3}$ Torr and the power RF (13.56 MHz) $150 \mathrm{~W}$ were maintened constant. The sample temperature was not kept constant but it was measured by a $\mathrm{K}$ type 
termopar not higher than $90{ }^{\circ} \mathrm{C}$ ). Along the deposition, the total gas flow in the process was $70 \mathrm{sccm}$.

\subsection{Four levels devices analysis}

A system with a $633 \mathrm{~nm}$ HeNe laser, three lens, a pin hole, a ccd camera and a bulkhead for the optical analysis was built (Figure 2).

\section{Results and Discussion}

Before DOE fabrication, the etch rate and roughness of optical glass to obtain the etch process control were studied. Silicon Dioxide $\left(\mathrm{SiO}_{2}\right)$ can easily be etched by $\mathrm{CF}_{4}$, but the optical glasses show difficulty for these processes because of the high contamination level. In etch process was used a $\mathrm{CF}_{4}$ pure plasma and $5{ }^{\circ} \mathrm{C}$ electrode temperature. Pressure was kept constant in 100 mTorr and power level was varied in order to obtain a process which has a reasonable carbon etch rate and minimized roughness.

Before the etch process, elipsometer and high step meter analyses were performed. The optical glass B 270 refraction index measured was 1.41. Etch rate was measured by high step meter for the different samples, as showed in the following graphic. Roughness was obtained by mechanical technique high step meter.

Higher etching process powers were used because those etch rates in brand glass for low power were very insignificant. In fact, it was showed in the graphic (Figure 3 ) that the higher the RF power is, higher the etch rate will be. Those results can be confirmed when

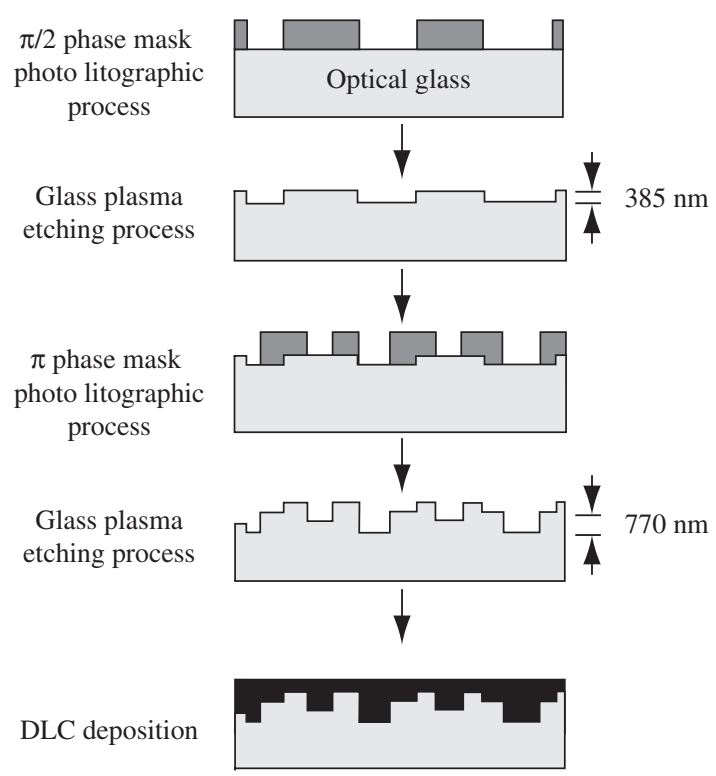

Figure 1. DOEs with four phase levels and amplitude modulation fabrication sequence. compared with the results showed in many other articles ${ }^{12-15}$. The values for maximum roughness, RMS roughness and RA roughness were between $9.9-40 \mathrm{~nm}, 0.7-5.4 \mathrm{~nm}$ and $1.7-15.8 \mathrm{~nm}$, respectively. So, it proves that the roughness do not vary too much with increasing RF power. Consequently, the process with higher RF power was chosen.

The values in pressure of 100 mTorr and an RF power level of $400 \mathrm{~W}$ for maximum roughness, RMS roughness and RA roughness, showed around $40 \mathrm{~nm}, 5.4 \mathrm{~nm}$ and $6.7 \mathrm{~nm}$ respectively. RMS roughness should be smaller than $10 \%$ of the wavelength of HeNe laser for the best performance of the diffractive optical element.

The RMS roughness was measured with an AFM. These results could be compared with the results obtained by high step meter.

The result for RMS roghness was low (Figure 4), under the $63 \mathrm{~nm}$ limit value (1/10 of HeNe laser wavelenght), but this value is two times bigger than the obtained by high step meter $(5.4 \mathrm{~nm})$. Before the glass superficial roughness analysis, it was deposited the DLC (refraction index 1.66) by sputtering with 484 thickness and 3.16 RMS roughness (obtained by high step meter).

The DLC roughness was measured with AFM technique.

The result showed for RMS roughness in AFM measurement (Figure 5) was very low $(0.086 \mathrm{~nm})$.

In order to analyse the diffractive optical elements working, it was chosen two Fresnel devices: one that forms an eagle and another that forms a butterfly image (Figure 6).

In Figure 6 are presented typical reconstructions from binary phase diffractive optical elements, Fresnel type. It can observe that there is no presence of diffraction zero order spot on the images that were rebuilt with good fidelity, but with excessive noise speckle (due to the glass etching process that is problematic).

In holograms of Fresnel type the reconstruction is not due to be symmetrically in relation to the reconstruction plan center. It was

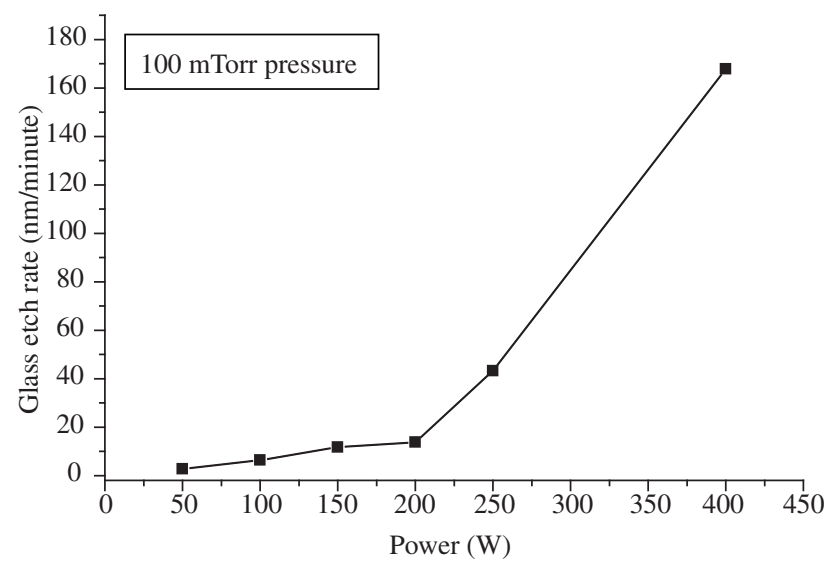

Figure 3. Glass etch rate versus power for 100 mTorr process.

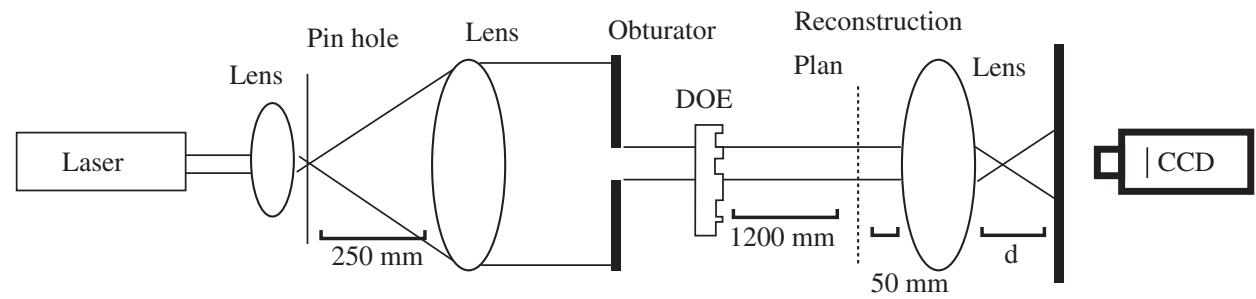

Figure 2. Optical analyses. The d distance controls the image magnificence. 


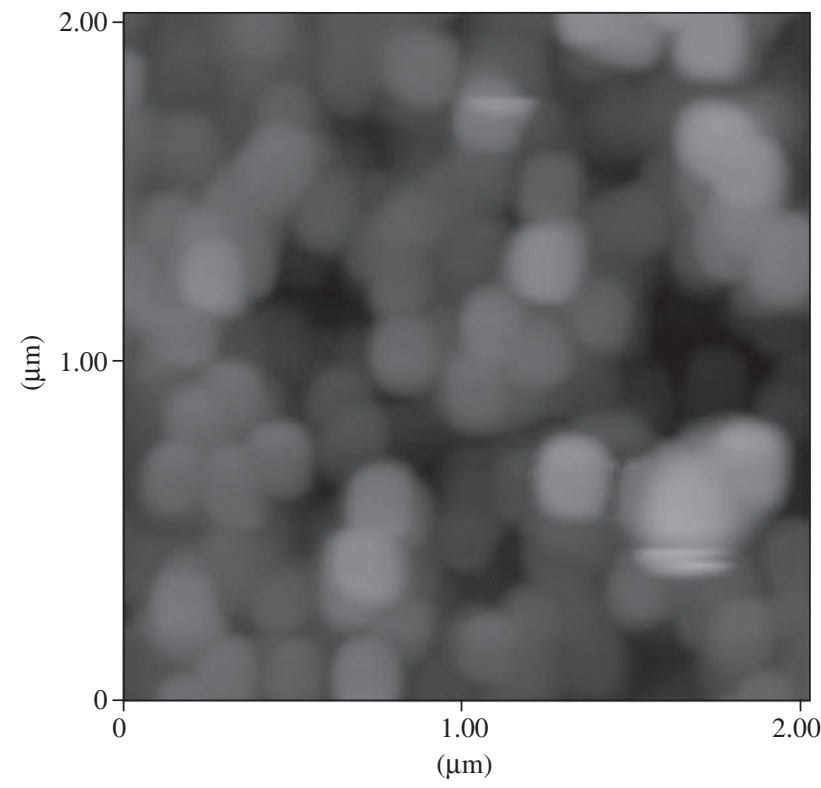

Image statistics

\begin{tabular}{|ll|}
\hline Img. Mean & $0.007 \mathrm{~nm}$ \\
Img. Rms (Rq) & $10.279 \mathrm{~nm}$ \\
Img. Ra & $7.962 \mathrm{~nm}$ \\
Img. Rmax & $603.301 \mathrm{~nm}$ \\
Img. Srf. area & \\
Img. Srf. area diff & \\
\hline
\end{tabular}

Figure 4. AFM analyses of 100 mTorr and $400 \mathrm{~W}$ sample.

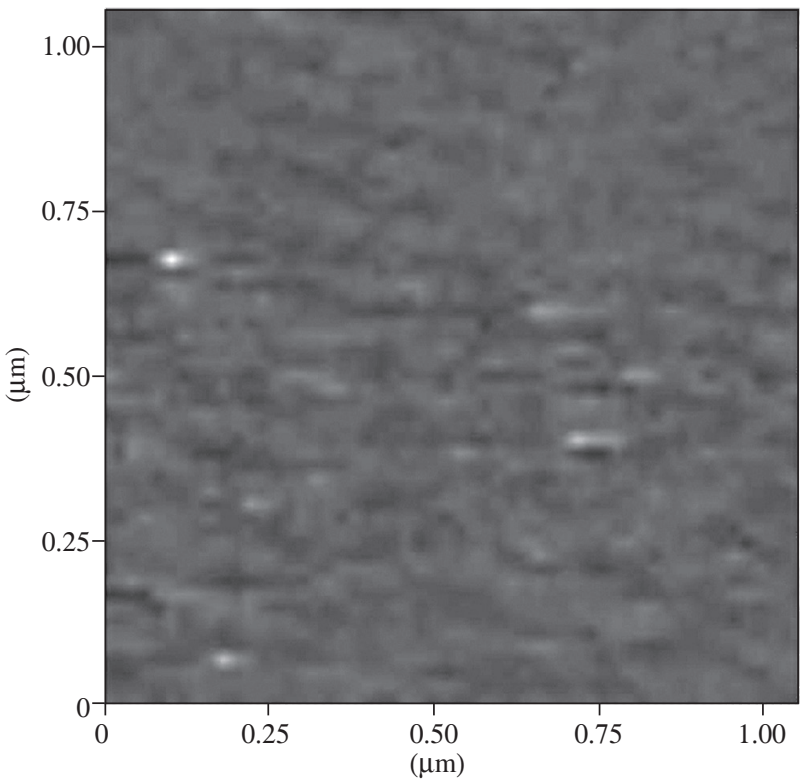

Image statistics

\begin{tabular}{|ll|}
\hline Img. Mean & $0.000000 \mathrm{~nm}$ \\
Img. Rms (Rq) & $0.086 \mathrm{~nm}$ \\
Img. Ra & $0.063 \mathrm{~nm}$ \\
Img. Rmax & $1.943 \mathrm{~nm}$ \\
Img. Srf. area & \\
Img. Srf. area diff & \\
\hline
\end{tabular}

Figure 5. AFM analyses of DLC surface. observed that there were no significant differences in the amplitude modulation for the devices covered by DLC and the elements without such thin film. To investigate this, an optical analysis was made of the surface elements. Transmittance results are shown in Figure 7.

The transmitance graphics showed for devices with DLC and without this thin film just prove that the same behavior occurs and the images produced by devices are in fact similar.

It would be ideal devices for to produce lasers with low wavelenghts (for example in blue range - Ar laser that has $481 \mathrm{~nm}$ wavelenght or in UV range - nitrogen laser that has 337 wavelenght). Another alternative to modulate the amplitude and, using $\mathrm{HeNe}$ laser, would be the deposition of a thick DLC layer.

In Table 1 is shown the amplitude modulation eficience from the transmitance difference (T\%) for the surface with and without
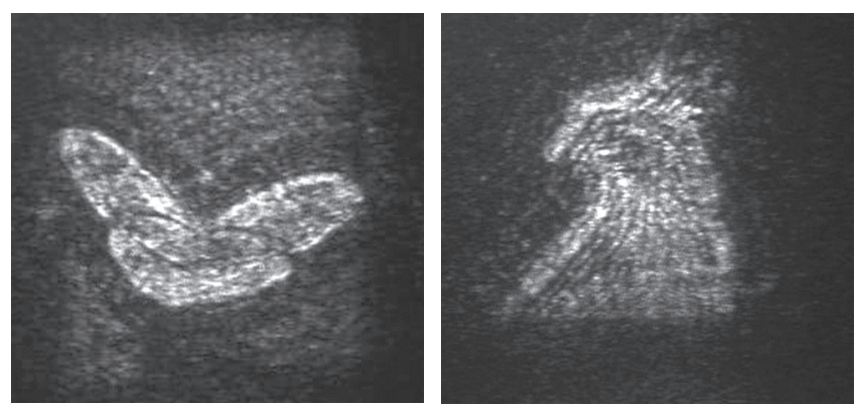

Figure 6. Device images that reproduce a butterfly and an eagle.

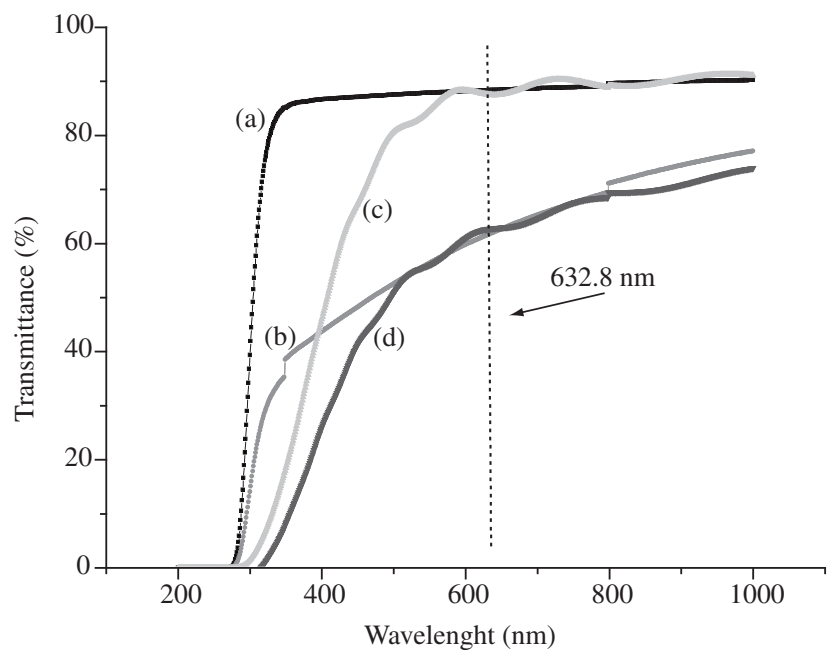
(a) Virgin glass
(c) DLC over virgin glass
(b) Etched glass
(d) DLC over etched glass

Figure 7. Virgin glass, etched glass and DLC over glass transmittance.

Table 1. Comparation of calculated results for different lasers.

\begin{tabular}{ccccc}
\hline $\begin{array}{c}\text { Laser } \\
(\mathrm{nm})\end{array}$ & $\begin{array}{c}\text { Difference } \\
\mathrm{T} \%\end{array}$ & $\begin{array}{c}\text { Limit } \\
\text { roughness } \\
(\mathrm{nm})\end{array}$ & $\begin{array}{c}\text { Time } \\
(\text { minutes })\end{array}$ & $\begin{array}{c}\text { Dmax } \\
(\mathrm{nm})\end{array}$ \\
\hline HeNe (632,8) & $\sim 1$ & $\sim 63$ & 6.5 & 770 \\
Argon (481) & 5 & $\sim 48$ & 5 & 587 \\
Cumarina (450) & 7.5 & $\sim 45$ & 4.6 & 549 \\
Nitrogen (337) & 30 & $\sim 34$ & 3.5 & 411 \\
\hline
\end{tabular}


DLC thin film in differents wavelenghts, as well the limit RMS roughness, etching process time (for same parameters used in this work: 100 mTorr pressure and $400 \mathrm{~W}$ RF power) and the desired thickness.

In order to make a more complete study, the total and diffuse reflectances were obtained by spectrophotometry technique with a integrative sphere for all materials. Based on the results, it was possible to calculate the RMS roughness. Using this method we can obtain the real roughness showed by the sample to the incident laser beam interaction.

The materials reflectance analyses is shown in Figure 8. For the plasma etched glass (under $100 \mathrm{mTorr}$ pressure and $400 \mathrm{~W}$ RF power, the same parameters used for diffractive devices manufacture), the difference between the values of the total reflectance R0 and diffuse reflectance RD was lower than $1.4 \%$ (at a $632.8 \mathrm{~nm}$ wavelength), while for the virgin glass, this difference exceeded $7.8 \%$. These values are reflected in the curves RD/R0 (Figure 8) for virgin glass and etched glass. Consequently, the observed roughness for etched glass is greater. In this work, what really matters are the obtained results for $632.8 \mathrm{~nm}$ HeNe laser wavelenght.

The measured roughness for DLC was $18.8 \mathrm{~nm}$ for HeNe wavelenght or, in other words, a close value of virgin glass. It indicates that the use of glass as substrate puts a limit in DLC RMS roughness, avoid a lower value. It can be concluded that the substrate would be a limiting factor in DOEs fabrication with DLC thin films.

The Equation for RMS roughness calculation is shown.

$$
\frac{R D}{R 0}=\left(\frac{4 \pi \Delta}{\lambda}\right)^{2}
$$

The values obtained for roughness by Equation $1^{17-22}$ indicates that both the glasses that suffered etching process and the DLC coated glasses have a high level of roughness. However these roughness are still within the limit of $63 \mathrm{~nm}$, thus not interfering with the performance of diffractive optical elements manufactured.

In fact, the etched glass presents a RMS roughness greater value $(\Delta)$ and this can be explained by the fact that the bombardment of the surface by ions during etching increases the roughness, affecting the substrate reflectance (Table 2).

It was also done a RMS roughness study of the DLC obtained by spectrophotometry for different types of lasers (Table 3).

We can observe that roughness decrease for lower wavelenghts. In fact, It's more beneficial to DOEs fabrication for lasers that operate in UV range.

\section{Conclusions}

In this work, DOEs based in glass substrate coated with DLC thin film with complex modulation (amplitude and phase) were obtained.

The transmitance graphics showed for devices with DLC and without this thin film just prove that they present the same behavior and the images produced by devices are in fact similar. There is a little difference in used laser wavelenght values (around 1\%).

The showed results confirm the possibility to manufactured DOEs to work in the UV region using the DLC as material for the amplitude modulation. The RMS roughness values for the DLC (for different wavelengths) were obtained optically very low, which is good for the device operation.

Besides, the DLC is a material that is compatible with many other substrates as quartz and polymers, and opens a big possibility for production of many DOEs types more eficients and with low cost.

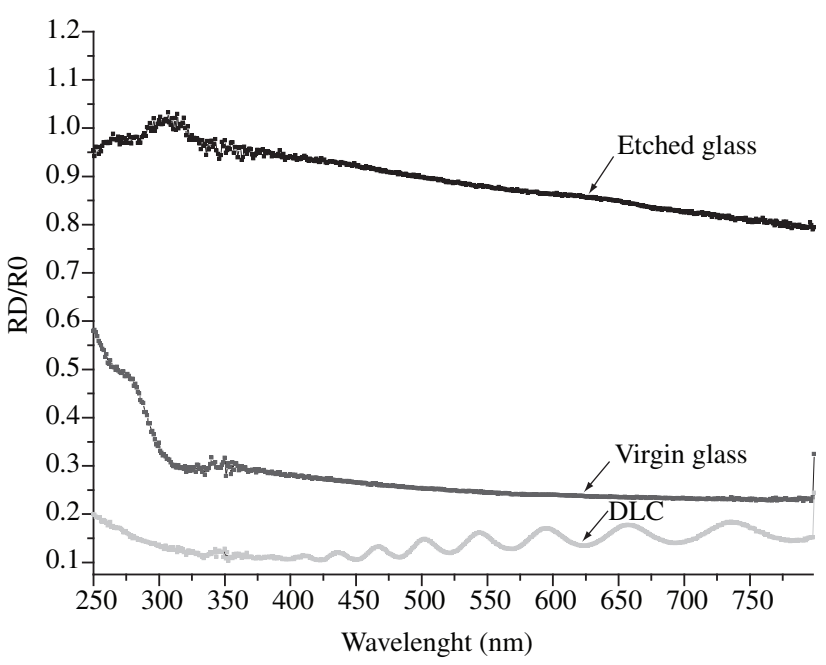

Figure 8. RD/R0 vs. wavelenght for different materials.

Table 2. Reflectances and RMS roughness results obtained by optical method.

\begin{tabular}{cccc}
\hline To $\lambda=632.8 \mathrm{~nm}$ & Virgin glass & Etched glass & DLC \\
\hline R0-RD & $7.8 \%$ & $1.4 \%$ & $10.42 \%$ \\
RD/R0 & 0.24 & 0.86 & 0.14 \\
Roughness & $24.7 \mathrm{~nm}$ & $46.6 \mathrm{~nm}$ & $18.8 \mathrm{~nm}$ \\
\hline
\end{tabular}

Table 3. DLC RMS roughness obtained with optical technique for different wavelenghts.

\begin{tabular}{lcc}
\hline$\lambda(\mathrm{nm})$ & $\mathrm{RD} / \mathrm{R} 0$ & Roughness $(\mathrm{nm})$ \\
\hline 632.8 & 0.14 & 18.8 \\
481 & 0.11 & 12.7 \\
450 & 0.10 & 11.3 \\
337 & 0.11 & 8.9 \\
\hline
\end{tabular}

\section{Acknowledgements}

The authors would like to thanks to Dr. José Fernando Diniz Chubaci, Mikiya Muramatsu, Dr. Sebastião Gomes do Santos, Dr. Luís da Silva Zambom, Mr. Alexandre Marques Camponucci and Mr. Nelson Ordonez for technical support and FAPESP, CNPq and CAPES for financial support.

\section{References}

1. Toma SN, Alexandrescu A, Cristea D, Muller R, Kusko M, Dumbravescu $\mathrm{N}$, Nascov V, Cojoc D. Binary phase reflective diffractive optical elements design and fabrication. IEEE. 2004; 2:401-404.

2. Kusko M, Cojoc D, Apostol D, Muller R, Manea E, Podaru C. Design and fabrication of Diffractive Optical Elements. IEEE. 2003; 1:167-170.

3. Rotich S, Smith JG, Evans AGR, Brunnschweiler AJ. Photoresist parabolas for curved micromirrors. Micromechanical Engineering. 1998; 8(2):108-110.

4. Li Q, Gao H, Dong Y, Shen Z, Wang Q. Investigation of diffractive optical element for shaping a gaussian beam into a ring shaped pattern. Optics \& Laser Technology. 1998; 30(8):511-514.

5. Silvennoinen R. et al. Diffractive element in optical inspection of paper. Optical Engineering. 1998; 37:1482-1487. 
6. Remillard JT, Marinelli MA, Fohl T, O’Neil DA. Diode laser illuminated automotive brake lamp using a linear fan-out diffractive optical element. Technical Digest of Diffractive Optics and Micro-Optics (DOMO). 1998; 10:192-194.

7. Volkel R, Herzig HP, Nussbaum P, Dandliker R, Hugle WB. Microlens array imaging system for photolithography. Optical Engineering, 1996; 35(11):3323-3330

8. Cirino GA. Fabricação de elementos ópticos difrativos empregando processos de microusinagem. [Tese de Doutorado]. São Paulo: Universidade de São Paulo; 2002.

9. Turunen J, Wyrowski F. Diffractive Optics for Industrial and Commercial Applications. Berlin: Akademie Verlag; 1997.

10. Goodman JW. Engineering Optics. New York: McGraw Hill; 1996.

11. Veldkamp WB. Wireless focal planes: on the road to amacronic sensors. IEEE. J. Quantum Electronics. 1993; 29(2):801-813.

12. Robertson J. Diamond-like amorphous carbon. Material Science and Engineering. 2002; 37:129-281.

13. Fieldsien J, Kim D, Economou DJ. SiO2 etching in inductively coupled C2F6 plasmas: surface chemistry and two-dimensional simulations. Thin Solid Films. 2000; 374(2):311-325.

14. Park JH, Lee NE, Lee J, Park JS, Park HD. Deep dry etching of borosilicate glass using SF6 and SF6/Ar inductively coupled plasmas. Microelectronic Engineering. 2005; 82(2):119-128.
15. Li X, Abe T, Esashi M. Deep reactive ion etching of Pyrex glass using SF6 plasma. Sensor and Actuators A. 2001; 87(3):139-145.

16. Wusirika RA. Study of the relation between the optical gap of diamondlike carbon and deposition conditions and the growth of diamond-like carbon on metallic substrates. [Tese de Mestrado]. Local de publicação: Case Western Reserve University; 1999.

17. Bennett JM, Dancy J H. Stylus profiling instrument for measuring statistical properties of smooth optical surfaces. Applied Optics. 1981; 20(10):1785-1802.

18. Duparre A, Ferre-Borrull J, Gliech S, Notni G, Steinert J, Bennett JM. Surface Characterization Techniques for Determining the Root-MeanSquare Roughness and Power Spectral Densities of Optical Components. Applied Optics. 2002; 41(1):154-171.

19. Guenther KH, Wierer PG, Bennett JM. Surface roughness measurements of low-scatter mirrors and roughness standards. Applied Optics. 1984; 23:3820-3836.

20. Elson JM, Rahn JP, Bennett JM. Relationship of the total integrated scattering from multilayer-coated optics to angle of incidence, polarization, correlation length, and roughness cross-correlation properties. Applied Optics. 1983; 22:3207-3219.

21. Bennett JM. Recent developments in surface roughness characterization. Meas. Sci. Technol.1992; 3(12):1119-1127.

22. Bennett JM. Introduction to Surface Roughness and Scattering. Michigan: Optical Society of America; 1989. 
